\title{
El Cuento del Demonio de Maxwell, una Propuesta Didáctica para la Enseñanza de Conceptos Básicos de Termodinámica
}

\author{
Javier E. Viau y Lucrecia E. Moro \\ Facultad de Ingeniería, Universidad Nacional de Mar del Plata, Juan B. Justo 4302, \\ Mar del Plata-Argentina (e-mail: grupocienciasbasicas@gmail.com)
}

Recibido Nov. 12, 2009; Aceptado Nov. 26, 2009; Versión final recibida Dic.22, 2009

\section{RESUMEN}

Se presenta el proceso de construcción de una propuesta pedagógica para la enseñanza de conceptos básicos de termodinámica basada en la utilización de relatos literarios. En este contexto y siguiendo los lineamientos didácticos sugeridos por algunos autores se presenta el diseño de una actividad que utiliza el cuento "El Demonio de Mawell" de Gamow, para ser implementada en clases de la Asignatura Química General I de la Facultad de Ingeniería de la Universidad Nacional de Mar del Plata en Argentina. Esta modificación en el enfoque de la enseñanza muestra como las narraciones que involucran contenidos científicos pueden ser empleadas por los docentes de ciencia como estrategia para aumentar el interés y motivación de los estudiantes. El cuento seleccionado, permite abordar conceptos termodinámicos a través de un modelo microscópico, que conduce a que los alumnos alcancen un mayor grado de racionalismo en su perfil epistemológico.

Palabras clave: termodinámica, Demonio de Mawell, propuesta didáctica, ciencia ficción, química

\section{The story of the Maxwell's Demon, a didactic proposal for the teaching of basic concepts in thermodynamics}

\begin{abstract}
The starting process of a pedagogic proposal for the teaching of basic concepts in thermodynamics based on the use of narratives is introduced in this paper. In this context, a pedagogical activity based on the story "Maxwell's Demon" of Gamow is designed, following the didactic outlines suggested by some authors. This activity was implemented in the course General Chemistry I, at Engineering Faculty of the Mar del Plata National University in Argentina. This approach employed as a teaching method shows how narratives involving scientific concepts can be used by science teachers as a strategy to enhance student's interest and motivation. The chosen story allows instructors to deal with thermodynamic concepts through a microscopic model leading the students to a higher standard of rationalism in their epistemological profile.
\end{abstract}




\section{INTRODUCCIÓN}

Los conceptos de energía, sus transformaciones y la entropía, presentan dificultades especiales en su aprendizaje, por lo que la enseñanza de los mismos ha sido tratada desde diversos enfoques (Erikson, 1979; Michinel y D’Alessandro, 1994; Martínez y Pérez, 1997). Como estos conceptos se encuentran dentro de los primeros a ser enseñados en todas las carreras de ingeniería de la Facultad de Ingeniería de la Universidad Nacional de Mar del Plata de Argentina, es una de las primeras dificultades de aprendizaje que deben superar los estudiantes de estas carreras.

Ante esta problemática, un grupo Ingenieros, docentes, especialistas en enseñanza de la ciencias, e investigadores del Área Física y Química Básica, siguiendo su línea de investigación y teniendo en cuenta que diversos autores han propuesto utilizar relatos literarios para enriquecer las clases de ciencias (Hellstrand y Ott, 1995; Campbell, 1999; Stanndard 2001; Brake y Thornton, 2003; Sierra, 2007), decidieron diseñar una estrategia de enseñanza para los conceptos de energía, sus transformaciones y la entropía utilizando un cuento de ciencia ficción.

\section{Narrativa, razón e imaginación}

Las narraciones pueden ser utilizadas por los docentes como estrategia para aumentar el interés de los estudiantes por los temas científicos, además de provocar en ellos procesos de reflexión y conceptualización. La narración tiene una forma, un ritmo y una estructura que permite relatar las historias del desarrollo del conocimiento. Además, la estructura narrativa es característica de las historias por medio de las cuales relatamos en términos generales el viaje educativo de la especie humana y los cambios que han marcado nuestro desarrollo como seres pensantes. Se trata ni más ni menos de las historias del desarrollo del conocimiento. La estructura narrativa es característica de las explicaciones de la historia de la conciencia humana como tal, o sea, de las historias por medio de las cuales relatamos en términos generales el viaje educativo de la especie humana y los cambios que han marcado nuestro desarrollo como seres pensantes. Se trata ni más ni menos de las historias del desarrollo del conocimiento. Otra forma de intermediación analógica para estimular la evolución conceptual es la narrativa de ficción, ya que las imágenes más poderosas son las que se originan desde las palabras (Mc Ewan y Egan, 1998).

En los escritos pedagógicos se ha marcado tradicionalmente una diferencia entre la razón y la imaginación considerando que pertenecen a categorías incompatibles. Bachelard (1993) fue un pionero en estudiar sus relaciones, ya que la imaginación está presente tanto en el trabajo del literato como en la investigación científica, mostrando que no existe ningún conflicto entre ellas. Por otra parte se verifica una conexión entre la imaginación y los ámbitos motivacional y emocional sobre todo cuando se puede mantener, basada en relaciones analógicas, una secuencia de imágenes mentales en forma de una narrativa. Así, la capacidad imaginativa será una asociación entre afectividad, analogías y narrativa.

Las relaciones entre los objetos de la naturaleza y las limitaciones de nuestra percepción imponen obstáculos epistemológicos. Para Bachelard, las representaciones espontáneas enmascaran una falsa simplicidad y no constituirán conocimientos científicos aquellos que provengan de causalidades primitivas: "Se pretende que la imaginación sea la facultad de formar imágenes. Pero ella es más bien la facultad de deformar las imágenes proporcionadas por la percepción". Este autor afirma que tanto la razón como la imaginación son potencias activas que trabajan su objeto y que coinciden al rechazar las percepciones inmediatas. El literato descubre, más que inventa, ya que toda imaginación apunta a un objeto y "la correlación del soñador con el mundo es una correlación fuerte".

En definitiva, la creación de modelos teoréticos de la ciencia, constantemente rectificados por nuevas hipótesis, tienen su correlato en la creatividad de imágenes del literato. La razón y la imaginación permiten una penetración metafísica de la realidad. Se advierte un carácter ontológico tanto en la labor científica como en la conciencia imaginativa, tratando de fusionarse con el objeto, y si bien esto no otorga posesión de la verdad, se adquiere una certidumbre objetiva que puede ser comunicada a los demás. Los procesos cognitivos de la imaginación literaria y de la racionalidad científica son los mismos. 


\section{Ciencia ficción}

La ciencia ficción es un género, una forma literaria con matiz distinto, limitado y particular. Siempre ha sido usado como una forma de examinar las relaciones entre ciencia, tecnología y sociedad representando una fuente de inspiración para el desarrollo científico y como una forma de difundir sus ideas. Dentro de la cultura popular ha adquirido prestigio ya que en parte sus anticipaciones se han cumplido y reviste una importancia especial con respecto a la actitud que toma la gente sobre la actividad científica. Aunque su mundo es restringido, en ocasiones se ha olvidado que el género pertenece a la literatura general. En ese sentido se debe considerar que incluye elementos que no se pueden tener en cuenta al valorar simplemente una obra literaria. Así, suelen estimarse la originalidad y el rigor científico mientras se deja de lado el punto de vista estilístico. Asimov (1982) diferencia tres tipos de literatura de "falso fondo": la fantasía, la sátira social y la ciencia ficción. La ciencia ficción provoca una sensación de asombro y de maravilla e introduce la indagación de temas sociales y filosóficos ampliando la concepción de nuestro universo.

La narrativa de ficción favorece la asimilación de los conceptos promoviendo la imaginación. Para Lakoff y Johnson (1991) la metáfora conceptual es un mecanismo cognitivo que permite que lo abstracto se comprenda en términos de lo concreto. La estructura cognitiva necesaria para la abstracción utiliza el mismo aparato conceptual que en las situaciones ordinarias del pensamiento cotidiano, es decir imágenes, esquemas y metáforas conceptuales. Y esto lleva a los procesos de modelización. Para estos autores el pensamiento metafórico consuma la unión entre razón e imaginación "en consecuencia, la metáfora es racional imaginativa". La razón abarca los procesos de ordenar, categorizar y realizar inferencias mientras que la imaginación crea puentes conceptuales que permiten la transposición de propiedades de un dominio de partida hasta un dominio de llegada.

Gamow fue un pionero en la utilización de historias en la enseñanza de la física, escribió una serie de relatos cuyo personaje, el Sr. Tompkins, un empleado de banco, asiste a conferencias de física moderna dictadas por un profesor. Estas conferencias provocan en él una serie de sueños en los cuales el Sr. Tompkins se ve transportado a ese fantástico mundo. Este autor reconoce que el secreto de su éxito tiene mucho que ver con la manera en que él llevó el formalismo de la física a representaciones concretas.

\section{El Demonio de Maxwell de Gamow}

El Demonio de Maxwell es el primer sueño del señor Tompkins contenido en el libro "La investigación del átomo" (Gamow, 1963). En los sueños, el señor Tompkins se enfrenta a los últimos descubrimientos de la física a través de sus aventuras imaginarias en el mundo atómico. El Demonio de Maxwell hace referencia a la utilización de una experiencia imaginaria creada por James Clerk Maxwell, quien en 1871 en su libro "Theory of Heat" bajo la sección "Limitación de la segunda ley de la Termodinámica" idea esta experiencia en donde dadas las condiciones por él planteadas se estaría en condiciones de violar las leyes estadísticas que rigen a los procesos termodinámicos, en particular la segunda ley de la Termodinámica. El nombre de Demonio de Maxwell fue dado por William Thompson en 1874 en su artículo "Kinetic Theory of the Dissipation of Energy". Gamow en este primer sueño, mediante un relato fantástico y una aventura imaginaria, introduce al lector en los principios básicos de la Termodinámica, no traicionando en modo alguno el rigor científico y recreando su relato con imágenes, metáforas y analogías.

\section{METODOLOGÍA}

En numerosos trabajos se ha señalado la utilidad de llevar al aula recursos didácticos motivadores como las artes plásticas, el cine y la literatura (Martín et al., 1992; García, 2006; Cachapuz, 2007; Palacios, 2007; Sierra, 2007). Siguiendo los lineamientos didácticos sugeridos por Reyes (2001) y ampliados por Sierra (2007) se ha diseñado una estrategia de enseñanza a los efectos de mejorar el proceso de aprendizaje, incorporando en el aula el cuento de Gamow "El demonio de Maxwell", el cual proporciona una visión microscópica de los conceptos termodinámicos: energía interna, conservación de la energía, calor, probabilidad y entropía. 
Esta visión microscópica de la termodinámica, en general no es característica en los cursos de química básica universitarios en donde la termodinámica es clásicamente enfocada de acuerdo con variables macroscópicas. El concepto de entropía es considerado como algo misterioso y difícil de comprender, sin embargo la conservación y la degradación de la energía no deberían ser conceptos contradictorios sino complementarios. La forma de presentar al alumno el concepto de entropía, que cuantifica la degradación, no puede dejar de lado a los modelos microscópicos ni a los aspectos estadísticos (Alonso y Finn, 1995) que son los que le permitirán comprender los términos corrientes y confusos de "orden" y "desorden". El análisis microscópico de las variables termodinámicas ayuda a desarrollar en el alumno un perfil epistemológico de carácter marcadamente racionalista que se resalta sobre el clásico perfil empírico que en general caracteriza a la formación en química (Bachelard, 2003).

La estrategia de enseñanza que se propone ha sido diseñada para ser implementada con alumnos del ciclo básico de las carreras de ingeniería, en la Asignatura Química General I dentro del eje temático de termodinámica y ha tenido en consideración las siguientes actividades pedagógicas (Sierra, 2007): i) Análisis y comprensión de la lectura: análisis de los aspectos epistemológicos y del contexto histórico del relato; ii) Guías motivadas de lectura; y iii) Ejercicios de representación

La propuesta metodológica incluye: i) - La lectura y discusión entre docentes y alumnos del cuento "El demonio de Maxwell" de Gamow, durante una hora de las asignadas para las clases prácticas, después de haber introducido los temas conceptuales de la termodinámica en las clases de teoría; ii) la realización por parte de los alumnos de una guía de actividades, dividida en dos fases, con objetivos diferentes; y iii) el debate entre docentes y alumnos, de la vinculación entre la guía de actividades con los ejercicios y problemas incluidos en la práctica tradicional de la asignatura.

\section{Guía de Actividades: Fase 1}

La Tabla 1 muestra una guía de actividades a realizar por los alumnos, una vez finalizada la lectura y discusión del cuento junto a los docentes. Esta fase tiene por objetivo que el alumno trabaje con el cuento de forma de reconocer su estructura, los conceptos termodinámicos que se tratan y, las metáforas y analogías que el autor utiliza. Los objetivos de cada una de las actividades se detallan a continuación:

1) El análisis literario, histórico y epistemológico está enfocado a despertar en el alumno la motivación que surge de la forma narrativa con la que Gamow describe los distintos procesos involucrados en el viaje imaginario realizado por el señor Tompkins. Por otra parte, es importante que el alumno reconozca al "Demonio de Mawell" como un elemento de ficción pero claramente necesario para explicar la evolución irreversible de la naturaleza.

2) Con el análisis científico conceptual se busca que el alumno reconozca los distintos conceptos físicos que involucran a la termodinámica contribuyendo a la conceptualización de los diferentes procesos y variables. Cabe destacar que en la narración del viaje fantástico realizado por el señor Tompkins, Gamow muestra y explica la realidad de ese mundo microscópico utilizando distintos modelos y metáforas para explicar lo que se observa en las distintas instancias del viaje.

3) Dentro del análisis científico metafórico / analógico, se rescatan tres frases con un claro tenor metafórico que emplea Gamow a lo largo del cuento. El objetivo del mismo es que el alumno modele el mundo microscópico e interprete dentro de ese modelo las metáforas utilizadas.

4) Con el análisis del contenido científico, preguntas y respuestas, se invita al alumno a que responda a las distintas variables y conceptos que más allá del cuento, pertenecen a la asignatura Química General I respecto del tratamiento de la termodinámica. Y se espera que, con una visión microscópica de los procesos involucrados evidencie un marcado perfil racionalista. 
Tabla 1: Guía de Actividades, Fase 1

\section{"El Demonio de Maxwell" de G. Gamow}

1) Análisis literario, histórico y epistemológico.
a) Mencione elementos del texto relacionados con posibles avances del conocimiento científico dentro de un contexto histórico de la ciencia.
b) A través de la ficción de la historia ¿cuál puede ser el mensaje del texto en un contexto del conocimiento científico?
c) Explique por qué este cuento puede leerse como ciencia ficción

2) Análisis científico conceptual.

Busque ejemplos que se mencionen en el cuento acerca de los siguientes conceptos físicos.
Energía interna y Calor
Procesos térmicos
Procesos espontáneos - Irreversibilidad;
"Orden" y "desorden"
Entropía

\section{3) Análisis científico metafórico / analógico.}

De una explicación de cada una de las siguientes frases

Pág. 16: "Lo que ocurre es que los procesos térmicos son muy similares, por lo que hace a su naturaleza, a los juegos de dados..."

Pág. 20: "El demonio de Maxwell es más bien un amigo servicial capaz de cambiar la trayectoria de cualquier molécula individual..."

Pág. 27: "¡Sagrada entropía! - exclamó su padre mirando enajenado el high-ball del señor Tompkins..."

4) Análisis del contenido científico, preguntas y respuestas.

Responda a las siguientes cuestiones
a) ¿Qué se quiere significar con la expresión "movimiento continuo"?
b) ¿Qué diferencia hay entre energía interna, temperatura y calor?
c) ¿Qué se entiende por "orden" y "desorden"?
d) ¿Puede haber un proceso que vaya del "desorden" al "orden" ?
e) ¿Qué es un proceso espontáneo?
f) ¿Qué es la entropía?
g) ¿Por qué dice el demonio de Maxwell que puede violar la ley de la entropía progresiva?

\section{Guía de Actividades: Fase 2}

La segunda fase de la guía de actividades consiste en un cuestionario con diez preguntas conceptuales extraídas de Physical Science Study Commitee (1970), que complementan a la guía de ejercicios tradicionales, la cual no contempla el enfoque microscópico del estudio de la termodinámica. La Tabla 2 muestra el mencionado cuestionario en el cual puede observarse que, si bien son básicos los conceptos y principios de la termodinámica abordados, las preguntas buscan que el alumno logre, después de la discusión del cuento y de haber realizado las actividades de la fase 1 , una marcada evolución conceptual hacia un perfil racionalista y darán cuenta en el marco del razonamiento del alumno, de lo que hemos denominado como la transferencia epistemológica que caracteriza a todo proceso de modelado (Viau et al., 2008).

\section{RESULTADOS}

Si bien este trabajo consiste en mostrar una propuesta de enseñanza basada en la utilización de la narrativa de ficción, la evaluación de los resultados de su aplicación consistirá en analizar la evolución del perfil epistemológico de los alumnos, antes y después de la instrucción. Se proyecta trabajar con dos grupos: un grupo control que será instruido de forma tradicional y un grupo experimental que dentro de las actividades de enseñanza incorporará la que aquí se propone. 
La elaboración de los perfiles epistemológicos será llevada a cabo de acuerdo a los lineamientos sugeridos y aplicados por los autores (Viau y Moro, 2009) que permitirá determinar las componentes realista, empirista y racionalista del perfil epistemológico resultante. Se espera que el grupo experimental muestre no solamente una marcada banda racionalista sino también una menor banda en el espectro que corresponde al realismo.

Tabla 2: Guía de Actividades, Fase 2

1) Si nos pudiéramos introducir dentro de un material con un diminuto martillo, y golpear alguno de sus átomos, ¿qué sucedería con la energía interna y la temperatura del material?

2) Una mezcla de gas hidrógeno con gas oxígeno se encuentra a una temperatura T. ¿Cuáles de las moléculas se mueven más rápido? Justifique la respuesta.

3) Los choques entre las moléculas de un gas, ¿incrementan la temperatura del mismo? Justifique la respuesta.

4) Dos recipientes de igual volumen contienen, uno de ellos $2 X$ moléculas de un gas $A$ y el otro $X$ moléculas de un gas $B$ cuya masa molecular es mayor que la de A como muestra la figura. Sabiendo que los dos recipientes se encuentran a igual temperatura, analice las siguientes afirmaciones, indique las que son correctas, y corrija las incorrectas:

a) La energía cinética media de las moléculas de $A$ es igual a la energía cinética media de las moléculas de $B$.

b) La velocidad media de las moléculas de $A$ es igual a la velocidad media de las moléculas de $B$.

c) La presión del gas $A$ es dos veces mayor que la presión del gas B.

d) La energía cinética total de las moléculas de A es igual a la energía cinética total de las moléculas de B.

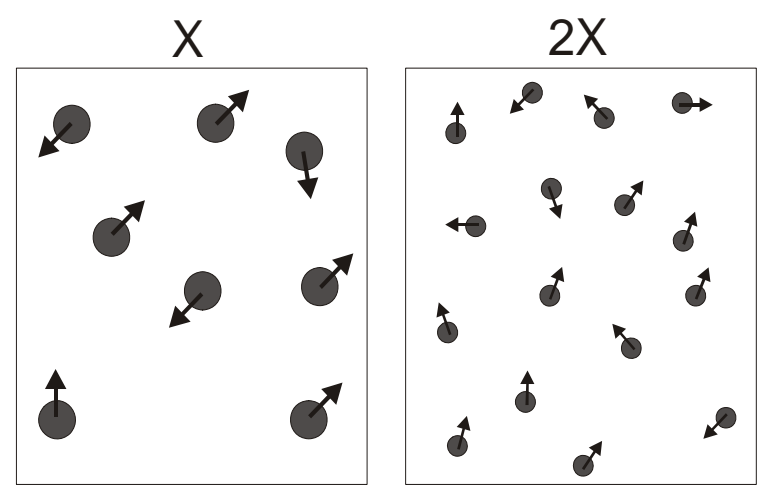

5) Explique ¿por qué no es posible en la práctica impulsar una nave extrayendo calor del océano para mover las hélices, arrojando por la borda el hielo resultante?

6) El enunciado de la segunda ley de la Termodinámica propuesto por Clausius, es el siguiente:

"El calor no pasa espontáneamente de un cuerpo frío a un cuerpo más caliente".

Explique por qué el funcionamiento de un refrigerador no viola el enunciado de Clausius.

7) Desde la perspectiva de la entropía, explique lo que sucede cuando una bala alcanza el reposo al chocar con una placa de acero.

8) Elabore una lista de todos los procesos en los que ha participado hoy, que disminuyeron la energía disponible del universo.

9) Explique de qué manera está implicada la entropía en la distinción entre el pasado y el futuro.

10) Explique qué puede sucederle a la entropía de cualquier sistema cerrado, es decir, de sistemas completamente aislados del resto del universo. 


\section{CONCLUSIONES}

Esta propuesta destaca que la capacidad de narrar es una condición del proceso de enseñanza y aprendizaje, de las formas más elaboradas del pensamiento y de la escritura. Bruner (1986) emplea la metáfora de un paisaje para explicar cómo la palabra y el relato comparten funciones narrativas: "El relato debe construir dos paisajes simultáneamente, el paisaje exterior de la acción y el interior del pensamiento e intención". La narrativa puede ser un excelente vehículo del pensamiento científico, ya que además de favorecer la formación integral de los alumnos habida cuenta de la riqueza de disciplinas involucradas (ciencias naturales, ingeniería, literatura, sociología, historia, ética), contribuye con la formación en competencias profesionales, ya que fomenta una combinación dinámica de conocimiento, comprensión, capacidades y habilidades.

La implementación de la propuesta dará lugar a que los alumnos universitarios que no consiguen responder satisfactoriamente situaciones problemáticas relacionadas con los conceptos de la termodinámica aún después de haber recibido un entrenamiento importante en ello, logren vencer las dificultades de aprendizaje al vincular la correspondencia entre el modelo macroscópico de las leyes de la termodinámica, (relaciones de energía que emplean magnitudes fenomenológicas) y el modelo cinético molecular de la materia.

\section{REFERENCIAS}

Alonso, M y E. Finn, An integrated Approach to thermodynamics in the introductory Physics Course, Physics Teacher, 5 (33), 296-310 (1995).

Asimov, I., “¿Hay alguien allí?” Editorial Bruguera, Barcelona, España (1982).

Bachelard, G., "La Filosofía del no", $1^{\circ}$ ed. En. francés 1940, Amorrortu, Buenos Aires, Argentina (2003).

Brake, M y R. Thornton, Science fiction in the classroon, Physics Education, 38 (1), 31-34 (2003).

Bruner, J., "Realidad mental y mundos posibles", Gedisa, Barcelona, España (1986).

Cachapuz, A. F., Arte y ciencia: ¿Qué papel juegan en la educación en ciencias?, Revista Eureka, 4 (2), 287-294 (2007).

Campbell, M., Oh Now I get It!, Journal of Engineering Education, 88 (4), $381-383$ (1999).

Erickson, G. L., Children's conceptions of heat and temperature, Science Education ${ }_{2} 63$ (2), 221230 (1979).

Gamow, G., "La investigación del Átomo", 2º ed., Fondo de Cultura económica, México (1963).

García, F. J., Cuando los mundos chocan, Revista Eureka, 2 (3), 268 -286 (2006).

Hellstrand, A. y A. Ott, The utilization of fiction when teaching the theory of relativity, Physics Education, 30 (5), 284-286 (1995).

Lakoff, G. y M. Johnson, “Metáforas de la vida cotidiana”, Cátedra, Madrid, España (1991).

Martín, M. J. y otros cuatro autores, Science fiction comes into the classrroom: Maelstrom II, Physics Education, 27, 18-23 (1992).

Martínez, J. M y B. A. Pérez, Estudio de propuestas alternativas en la enseñanza de la termodinámica básica, Enseñanza de las Ciencias, 15 (3), 287-300 (1997). 
Mc Ewan, H. y K. Egan, La narrativa en la enseñanza, el aprendizaje y la investigación. Amorrortu editores, Buenos Aires, Argentina (1998).

Michinel J. L. y A. D'Alessandro, El concepto de Energía en los libros de texto: de las concepciones previas a la propuesta de un nuevo lenguaje, Enseñanza de las Ciencias, 12 (3), 369-379 (1994).

Palacios, S. L., El cine y la literatura de ciencia ficción como herramientas didácticas en la enseñanza de la física: una experiencia en el aula, Revista Eureka, 4 (1), 106-122 (2007).

Physical Science Study Comité, "Física”, Editorial Reverté, Barcelona, España (1970).

Reyes, J., "Teoría y didáctica del género ciencia ficción”, Magisterio, Bogotá, Colombia (2001).

Sierra, C., Fortalezas epistemológicas y axiológicas de la ciencia-ficción: un potosí pedagógico mal aprovechado en la enseñanza y divulgación de las ciencias, Revista Eureka, 4 (1), 87-105 (2007).

Stannard, R., Communicating physics through story, Physics Education, 36 (1), 30-34 (2001).

Viau J. y otros tres autores, La Transferencia epistemológica de un modelo didáctico analógico. Revista Eureka, 5 (2), 170-184 (2008).

Viau, J. y L. Moro, "El perfil epistemológico de Bachelard y los modelos didácticos: la transferencia epistemológica en alumnos de nivel medio", VI Jornadas de Investigación en Educación: Investigación, conocimiento y protagonismo de los actores en el campo educativo, Córdoba, Argentina, 1 al 3 de julio (2009). 